\title{
The death of Porthos, or the first description of vertebrobasilar insufficiency in fiction
}

\author{
Vagn Rønnov-Jessen
}

Vertebrobasilar insufficiency is a comparatively young clinical entity. Transient cerebral attacks were described in the last 40 years of the nineteenth century by Raynaud in 1862, Weiss in 1882, Bastian in 1886, and Osler in $1896 .{ }^{1}$ Basilar thrombosis was first described by Hayem in $1868,{ }^{2}$ but it was not until the clinical and pathological studies of Kubik and Adams were published in $1946^{3}$ that doctors' interest was really aroused. The term cerebrovascular insufficiency was introduced by Denny-Brown in $1951 .^{+}$

Alexandre Dumas wrote his books about the three musketeers in the years 1844-7. In the last part of Le Vicomte de Bragelonne ou dix ans plus tard he described the death of the musketeer Porthos.

\section{The giant musketeer}

Porthos was about 55 years old. He was a giant of a man, big, strong as a bull and, furthermore, fat, weighing about $130-140 \mathrm{~kg}$. He had never had a day of illness except when he was wounded in a fight.

One day, when fleeing from Louis XIV's soldiers, he felt sick and depressed. He told Aramis - another of the musketeers-his family story. His grandfather, Antoine, had been three times as strong as Porthos. One day during a hunt he had suddenly felt a weakness of his legs. Despite it he continued the hunt, but again his legs failed, and he was killed by a wild boar.

One evening many years later his father, Gaspard, twice as strong as Porthos, suddenly felt his legs fail, a sensation he had never experienced before. Remarking that there was no risk of his meeting a wild boar, he succeeded in getting up, but when he tried to descend the staircase his legs failed again and he fell and died from cerebral concussion.

Aramis could not understand why Porthos told him this, but Porthos explained that at that moment he was feeling quite well but earlier that day he had vacillated and sunk to the ground. This was the fourth time it had happened to him.

The next morning after a long march Porthos and Aramis arrived at a cave where they and three others took shelter. In the next hours they were attacked by about 90 soldiers. Porthos killed 10 of them with an iron bar, and many others were shot. The attack continued, and Porthos took a barrel of powder weighing about $30-35 \mathrm{~kg}$, ignited the fuse, balanced the barrel in his hand, and then with a violent one arm throw hurled the barrel against the soldiers. A few seconds later he felt his legs weakening and his knees bending. In vain he tensed all the muscles in his body, but he fell to his knees. On account of the enormous strength of his arms and hands he succeeded in getting up a few seconds later by clinging to the rocks of the cave, but he could not take one step. He tried to speak, but it resulted only in incoherent stuttering. Suddenly the barrel exploded and he regained his strength, but it was too late. He was crushed by falling rocks.

\section{A life of excess}

As mentioned earlier, Porthos was about 55 years old. Like his father and grandfather he was a large man and rather fat. During his life he had eaten a lot of meat, which contained an abundance of saturated fatty acids. Furthermore, he was very fond of wine in great quantities. We can assume that he had atherosclerosis, being a typical victim of this degenerative disease.
Dumas described Porthos's symptoms thoroughly Firstly, they were provoked by a violent throw with one arm, which produced an extreme degree of rotation or extension of the neck, one of the known causes of acute vertebrobasilar insufficiency. Secondly, he had weakness or rather paralysis of both legs a few seconds after the throw. Thirdly, he was unable to coordinate the muscles of the body (ataxia). Finally, he stuttered (dysarthria), a symptom that had never been mentioned before in any of the books about the three musketeers. Porthos's symptoms are typical of transitory affection of the upper spinal cord and lower brain stem (insufficiency of anterior spinal and vertebral arteries). ${ }^{6}$

How could Dumas give such a clinical description? $\mathrm{He}$ and his father were both large strong men much like Porthos in stature. Dumas could not have known about the symptoms from his father because he had died in 1806 , when Dumas was 3 years old. Neither could it be from personal experience. Dumas was 45 when the novel was published in 1847, and he lived for 23 years after that. Nevertheless, he gave the first clinical description of this illness in fiction many years before it was described in the medical texts.

Until anything else is documented I will give Alexandre Dumas the credit for describing the clinical picture of transient vertebrobasilar insufficiency.

1 Wilson SAK, Bruce AN. Neurologv. Vol 3. London: Butterworth, 1955:1399. 2 Loeb C, Mever JS. Strokes due to vertebro-basilar disease. Springfield, Illinois: Charles C Thomas, 1965:116.

Kubik CS, Adams RD. Occlusion of the basilar artery. A clinical and pathological study. Brain 1946;69:73-121

+ Denny-Brown D. The treatment of recurrent cerebrovascular symptoms and the question of vasospasm. Med Clin North Am 1951;35:1457-74.

5 Dumas A. Le Vicomte de Bragelonne ou dix ans plus tard, VI. Paris: Louis Conard, 1929. (First published in 1847 in Paris.)

6 Toole JF. Cerebrovascular disorders. New York: Raven Press, 1984:101-6.

\section{WORDPOWER}

Following the lead of Philip Howard into the deeper recesses of the English language ("Word watching," The Times), I have set out a selection of medical terms along with a range of suggested meanings. While few of these may form part of the everyday vocabulary of today's clinician, many of them describe conditions that are commonplace. The correct answers and their derivations are on page 1703.-DAVID MAXWELL, Guy's Hospital, London SE 1 9RT

\section{Amazia}

(1) non-development of the breast

(2) excessively aggressive behaviour in a woman

(3) facies of one looking constantly surprised

\section{Caligo}
(1) extravagant behaviour
(2) metal foot brace

(3) dimness of vision

\section{Canities}

(1) whitening of hair on the head

(2) hangdog look

(3) koilonychia

\section{Carphology}

(1) abnormal lachrymation

(2) self induced trauma to buccal mucosa

(3) delirious plucking at bedclothes

More words on page 1685 